\title{
Olhar Docente Acerca da Prática com Jogos e Tecnologias nas Intervenções da Sala de Recursos Multifuncionais
}

\section{Teachers' Perspective on Practice with Games and Technologies in Interventions within Multifunctional Resource Classrooms}

\author{
Maria Mara Sílvia Spurio ; Luciane Guimarães Batistella Bianchini*a; Nielce Lobo da Costa ${ }^{\text {abc }}$; Adriana Von Stein ${ }^{\circ}$ \\ ${ }^{a}$ Unopar, Programa de Pós-Graduação Stricto Sensu em Metodologias para o Ensino de Linguagem e suas Tecnologias. PR, Brasil. \\ 'buniversidade Anhanguera de São Paulo, Programa de Pós-Graduação Stricto Sensu em Ensino e Ciências da Saúde. SP, Brasil \\ 'Universidade Anhanguera de São Paulo, Programa de Pós-Graduação Stricto Sensu em Educação Matemática. SP, Brasil. \\ *E-mail: luannbi@hotmail.com
}

\begin{abstract}
Resumo
As intervenções educacionais que integram jogos às tecnologias digitais têm sido motivadas a fim de tornar o ensino significativo aos alunos, por se tratar de uma metodologia ativa e também por este tipo de hábito lúdico ser comum à geração atual. Mas, e no caso do professor do Atendimento Educacional Especializado (AEE), como ele considera tal integração à sua prática com alunos que apresentam Necessidades Educacionais Especiais (NEE)? Este estudo, caracterizado como qualitativo objetivou conhecer professores atuantes no AEE, suas práticas pedagógicas com jogos, bem como verificar suas percepções com relação ao uso dos jogos e da tecnologia para aprendizagem dos alunos com NEE no ensino fundamental. Para a coleta de dados foi realizada entrevista com cinco docentes do AEE que atuam em um munícipio da região norte do estado do Paraná. Os dados foram analisados qualitativamente e os resultados da pesquisa indicaram que a maioria das professoras sabe utilizar os jogos digitais, embora duas docentes (P2 e P4) informassem ter dificuldades, por falta de conhecimento e tempo para se dedicar à aprendizagem de determinado jogo. Quanto às suas percepções, todas as entrevistadas reconhecem a importância de jogos e tecnologias para a geração de alunos na atualidade, até mesmo no caso da proposta inclusiva na Sala de Recursos Multifuncionais (SRM). Este estudo concluiu que as percepções docentes se articulam à prática do professor, por isso refletir sobre como o professor concebe os jogos e tecnologias na SRM poderá contribuir para novas propostas junto aos alunos e suas NEE.
\end{abstract}

Palavras-chave: Ensino. Aprendizagem. Recursos Lúdicos Digitais. Atendimento Educacional Especializado.

\begin{abstract}
Educational interventions which integrate games with digital technologies have been encouraged to make teaching meaningful to students, since it is an active methodology and also due to the fact that this type of playful habit is common among the current generation. But, and in the case of the Specialized Education Service teacher (AEE), how does he/she consider such integration with his /her practice concerning students presenting Special Education Needs (NEE)? This study, based on a qualitative approach, was carried out to investigate how teachers act in AEE, their pedagogical practices with games, as well as to gain their perceptions concerning the use of games and technologies to further learning by NEE students at grade/junior high school level. To collect the data one carried out interviews with five AEE teachers working in a county located in northern Paraná State. Such data underwent a qualitative analysis and the research results showed that most of the teachers know how to use digital games, although two of them (P2 and P4) reported to have difficulty, due to lack of familiarity with it and time to get acquainted with the game at issue. Concerning their perceptions, all the interviews acknowledged the importance of games and technologies for current students, even for the inclusive proposal within the Multifunctional Resource Classroom (SRM). This study concluded that teachers ' perceptions are articulated with their practice and therefore the pondering on how the teacher conceives games and technologies in SRM may contribute to further new proposals jointly with NEE students.
\end{abstract}

Keywords: Teaching. Learning. Digital Playful Resources. Specialized Education Service.

\section{Introdução}

As mudanças decorrentes da inserção das Novas Tecnologias da Informação e Comunicação (NTIC) atingem todos os setores da sociedade, ao mesmo tempo que novas demandas e desafios surgem. No caso da educação cabe considerar a necessidade de busca por estratégias de ensino que atendam a um contexto diversificado de alunos com necessidades distintas.

Ao se voltar o olhar especificamente para os alunos que necessitam de Atendimento Educacional Especializado (AEE) é importante considerar ações pedagógicas efetivas que promovam sua aprendizagem e desenvolvimento. Um dos documentos que ressalta as práticas pedagógicas para os alunos está na Política Nacional na Perspectiva da Educação Inclusiva (BRASIL, 2008), ao indicar que as atividades a serem realizadas devem ser distintas daquelas da sala comum, a fim de atender os alunos em suas especificidades (KASSAR, 2011).

É neste contexto que se incluem as atividades mediadas por jogos. O jogo é considerado como estratégia de ensino caracterizada como metodologia ativa por autores como Moran (2015), Bianchini, Arruda e Gomes (2015) e Valente, Almeida e Geraldini (2017).

Sobre os jogos, Diesel et al. (2018) explicam que estes recursos se apresentam sob diferentes modalidades que podem contribuir para a construção 
do conhecimento, sejam eles: jogos de imaginação, de regras, psicomotores, de construção, entre outros. A questão é que, em toda atividade mediada por jogos em processos de escolarização, a intervenção do professor é importante, uma vez que a ação docente deve guiar-se pelo propósito de promover aprendizagem (MARTINS; BRIDI, 2016; DIESEL et al., 2018).

Outro aspecto sobre o jogo é que, na atualidade, ele se apresenta predominantemente integrado às tecnologias digitais (EVANGELISTA, 2018; PINHEIRO, 2020) e, por esta razão, adquire status de valor social entre os alunos, visto que a maioria os utiliza fora do contexto escolar (LÉVY, 2010).

Nesse sentido, ao relacionar o jogo às tecnologias no AEE, pode-se abrir caminhos para práticas pedagógicas significativas à geração atual, como também promover resultados inclusivos, em que todos se beneficiem - educandos e educadores (DUK, 2006).

Especificamente sobre os jogos integrados às tecnologias digitais e aplicados no AEE: O que as pesquisas apresentam de resultados? Spurio (2019) buscou responder a uma questão semelhante a esta por meio de levantamento bibliográfico, objetivando investigar se o AEE ofertado em SRM utiliza jogos digitais na prática com os alunos e quais seriam estes jogos.

A autora supracitada identificou 38 trabalhos sobre o tema, sendo 25 dissertações e 13 teses. Destes, 16 trabalhos apresentaram jogos digitais (Loqui-libras, Software Hércules e Jiló no Mundo da Matemática, Softwares Alfabetização Fônica, Jogos de Vídeo Game, Software Jogo Virtualmat, Softwares de Acessibilidade Dosvox e Virtual Vision); e 22 eram jogos de mesa (Jogo de Tabuleiro, Jogo de Alfabetização, Jogo Dominó, Jogo Bingo, Jogo da Memória, Jogo Trilha e Jogos de Linguagem).

$\mathrm{Na}$ análise dos trabalhos, Spurio (2019) observou que os jogos de mesa ou digitais são utilizados pelos professores praticamente na mesma proporção. Conforme as pesquisas, não há uma preferência entre um e outro, ambos são utilizados na prática do professor do AEE como instrumento para a aprendizagem dos alunos.

Outro aspecto analisado pela referida autora diz respeito à possibilidade de adaptação do jogo digital ou de mesa, conforme a NEE do aluno. Nas intervenções apresentadas nas pesquisas, os jogos foram aplicados para a maioria das deficiências: auditiva, visual, intelectual, paralisia cerebral/ deficiência física e dificuldade de aprendizagem. Spurio (2019) conclui que a inclusão dos alunos com NEE no âmbito educacional requer ações pedagógicas diferenciadas e nas pesquisas que analisou ainda existe "um número pequeno de jogos digitais" utilizados na prática dos professores no AEE.

Diante do exposto, cabem as seguintes reflexões: Se na atualidade tem-se uma geração que valoriza a tecnologia, como os professores do AEE concebem a contribuição dos jogos integrados às tecnologias para o aprendizado dos alunos com NEE?

Conhecer o professor do AEE, suas práticas pedagógicas com jogos, bem como verificar suas percepções com relação ao uso dos jogos e da tecnologia para aprendizagem dos alunos com NEE nos anos iniciais do ensino fundamental foi o objetivo deste trabalho, que entrevistou cinco professoras do AEE que atuam em um munícipio da região norte do estado do Paraná.

\section{Material e Métodos}

Para atender aos objetivos de conhecer as práticas pedagógicas com jogos e verificar as percepções dos participantes sobre o uso de jogos digitais na SRM realizouse uma pesquisa caracterizada como qualitativa. Para Minayo (2012, p.57), a pesquisa qualitativa é importante para estudos relativos às "representações e crenças, das relações, das percepções e opiniões, ou seja, dos produtos das interpretações que os humanos fazem durante suas vidas, da forma como constroem seus artefatos materiais e a si mesmos, sentem e pensam".

A pesquisa foi submetida ao Comitê de Ética em Pesquisa envolvendo Seres Humanos e obteve parecer favorável sob $\mathrm{n}^{\circ}$ 2.650.525. Elegeu como critério de seleção dos participantes: ser professor do AEE e atuante em escolas que tenham este atendimento com alunos dos anos iniciais do ensino fundamental.

Participaram da pesquisa cinco professoras que se enquadraram aos critérios estabelecidos de escolas diferentes da Rede Municipal de Educação da Região Norte do Paraná - Anos Iniciais do Ensino Fundamental, que têm as SRMs.

Para a coleta de dados realizou-se uma entrevista estruturada com 24 questões abertas e fechadas, das quais 12 foram selecionadas para discussão neste artigo.

$\mathrm{Na}$ análise, a interpretação dos dados ocorreu mediante tratamento qualitativo dos relatos das participantes, com base em dois eixos elencados: 1) Perspectiva docente sobre o jogo na prática do AEE; e 2) Perspectiva docente sobre o jogo e tecnologias na prática do AEE.

\section{Resultados e Discussão}

Para conhecer o AEE e as práticas adotadas por meio de jogos se faz necessário conhecer as professoras e suas percepções com relação ao uso dos jogos e da tecnologia para aprendizagem dos alunos com NEE.

As cinco professoras trabalham em escolas diferentes da Rede Municipal. O quadro 1, a seguir, apresenta um panorama geral das participantes e, por questões éticas do sigilo, elas foram identificadas como P1, P2, P3, P4 e P5. 
Quadro 1 - Professoras do AEE

\begin{tabular}{|c|c|c|c|c|c|c|}
\hline & Graduação & Especialização & Idade & $\begin{array}{l}\text { Tempo de Atuação } \\
\text { e Níveis de Ensino }\end{array}$ & $\begin{array}{c}\text { Tempo de Atuação } \\
\text { no AEE } \\
\end{array}$ & $\begin{array}{l}\text { Alunos/AEE Instrução no } \\
\text { 09/ 2018 SUED/ SEED-PR }\end{array}$ \\
\hline P1 & Pedagogia & $\begin{array}{l}\text { Psicopedagogia } \\
\text { Educação Especial }\end{array}$ & 35 & \begin{tabular}{|l|}
14 anos \\
Ed. Infantil, \\
Anos Iniciais e \\
Finais do Ensino \\
Fundamental, Ensino \\
Médio \\
\end{tabular} & $\begin{array}{l}1 \text { ano e } \\
3 \text { meses }\end{array}$ & $\begin{array}{l}\text { TEA, DI } \\
\text { TGD e Paralisia Cerebral. }\end{array}$ \\
\hline $\mathbf{P 2}$ & Pedagogia & $\begin{array}{l}\text { Psicopedagogia } \\
\text { Mestrado em Educação } \\
\text { Especial }\end{array}$ & 29 & $\begin{array}{l}08 \text { anos } \\
\text { Ed. Infantil, Anos } \\
\text { Iniciais do Ensino } \\
\text { Fundamental } \\
\end{array}$ & 2 anos & TDAH e TEA \\
\hline P3 & Matemática & $\begin{array}{l}\text { Educação Matemática e } \\
\text { Educação Especial }\end{array}$ & 48 & $\begin{array}{l}29 \text { anos } \\
\text { Ed. Infantil, } \\
\text { Anos Iniciais e } \\
\text { Finais do Ensino } \\
\text { Fundamental } \\
\end{array}$ & 4 anos & $\begin{array}{l}\text { TEA, } \\
\text { TDAH, } \\
\text { Dificuldade Específica }\end{array}$ \\
\hline P4 & Pedagogia & \begin{tabular}{|l} 
Educação Inclusiva, \\
Libras, Educação \\
Especial, Gestão Escolar, \\
Neuroaprendizagem e \\
Psicopedagogia
\end{tabular} & 36 & $\begin{array}{l}12 \text { anos } \\
\text { Ed. Infantil, Anos } \\
\text { Iniciais e Finais do } \\
\text { Ensino Fundamental }\end{array}$ & 4 anos & $\begin{array}{l}\text { TEA, Dificuldade Específica, } \\
\text { TDAH, Múltiplas } \\
\text { Deficiências }\end{array}$ \\
\hline P5 & Letras & $\begin{array}{l}\text { Educação Especial, } \\
\text { Psicomotricidade, } \\
\text { Psicopedagogia e Gestão } \\
\text { Escolar }\end{array}$ & 43 & $\begin{array}{l}18 \text { anos } \\
\text { Ed. Infantil, Anos } \\
\text { Finais do Ensino } \\
\text { Fundamental e } \\
\text { Ensino Médio }\end{array}$ & 4 anos & $\begin{array}{l}\text { Síndrome de Down, DI, TEA } \\
\text { e TDAH. }\end{array}$ \\
\hline
\end{tabular}

Fonte: Spurio (2019).

Todas as participantes atuantes na SRM são do sexo feminino, sendo três com formação em Pedagogia, uma em Letras e outra em Matemática. Gomes (2008) chama a atenção para o fato de que a predominância feminina na profissão docente, representada pelo curso de Pedagogia, tem relação direta com o fato de esta ter sido uma das primeiras profissões a se abrir para o trabalho feminino com aprovação social.

Sobre a feminização do magistério, Silva (2002) considera que isto ocorreu como luta das mulheres para se estabelecerem profissionalmente, em razão da associação do trabalho educativo à condição da maternidade.

As professoras participantes da pesquisa possuem formação continuada com Especialização em Psicopedagogia; Educação Especial; Educação Matemática; Educação Inclusiva; Libras; Gestão Escolar; Neuroaprendizagem; Psicomotricidade e Mestrado em Educação Especial. Nóvoa (1997, p.25) pondera sobre a formação do professor no sentido de que esta "[...] não se constrói por acumulação (de cursos, de conhecimentos e de técnicas), mas, sim através de um trabalho de reflexibilidade crítica sobre as práticas de re(construção) permanente de uma identidade pessoal".

O tempo de atuação das participantes na função de professor encontra-se entre 8 e 29 anos, nos níveis de Ensino da Educação Infantil, $1^{\circ}$ ao $9^{\circ}$ ano do Ensino Fundamental e Ensino Médio. Especificamente como professor do AEE, as participantes têm experiência em torno de 1 ano e 3 meses a 4 anos.

\subsection{Eixo 1: Perspectiva docente sobre o jogo na prática do AEE}

A prática no AEE apresenta especificidades e muitos estudos (COELHO, 2010; MACEDO, 2007; MACEDO; PETTY; PASSOS, 2005, 2010; BIANCHINI; ARRUDA; GOMES, 2015) indicam os jogos como estratégia importante e significativa para o aluno enquanto ele está aprendendo.

As professoras participantes desta pesquisa foram questionadas se consideram a prática com jogos importante no trabalho realizado no AEE e por quê.

Todas consideraram como fundamental o trabalho com jogos na SRM, pois a ludicidade favorece a aprendizagem, motiva o aluno a aprender. Cabe destacar a seguinte fala da professora

todas as minhas atividades são pautadas em jogos, é com jogos que você consegue desenvolver as habilidades de forma lúdica e diferenciada, que o aluno vai absorver mais facilmente, principalmente porque tem necessidades diferentes dos outros alunos. P1

Segundo Macedo (2007, p. 15), é preciso

[...] cuidar da dimensão lúdica das atividades escolares e possibilitar que as crianças pudessem ser protagonistas, isto é, responsáveis por suas ações, nos limites de suas possibilidades de desenvolvimento e dos recursos mobilizados pelos processos de aprendizagem.

Cotonhoto, Rossetti e Missawa (2019) ponderam que o jogo é defendido por vários autores que o pesquisam e enfatizam que, em seu aspecto afetivo, o jogo motiva o aluno à ação, por isso torna-se importante aos educadores integrá-lo 
à prática pedagógica.

Também foi perguntado às professoras como elas organizam um Plano de AEE que inclui os jogos. A escolha do jogo e o modo como é utilizado por elas merecem alguns destaques: P1, por exemplo, inclui o jogo, e a escolha deste é feita com base nas habilidades que pretende desenvolver com os alunos.

Segundo Grassi (2008, p. 124), durante o processo de jogar:

Os participantes são incentivados a jogar bem e a se aperfeiçoar; as funções mentais superiores são colocas em movimento, são estimuladas, exercitadas desenvolvemse e se aperfeiçoam na busca por melhores resultados; disciplina, a concentração, a perseverança e a flexibilidade são valorizadas; aperfeiçoam-se esquemas de ação, criam-se e se descobrem estratégias mais eficientes para o jogo.

A professora P2 relatou que o seu planejamento nunca fica restrito ao jogo e que a utilização deste recurso dependerá da disposição dos alunos, que oscila muito durante os atendimentos e ainda completa dizendo "que às vezes o que queremos no plano não é atingido, ou temos que reelaborar tudo na hora". Sobre o planejamento, Libâneo (2013, p.245) ressalta que sua elaboração é uma tarefa do professor "que inclui tanto a previsão das atividades em termos de organização e coordenação em face dos objetivos propostos, quanto a sua revisão e adequação no decorrer do processo de ensino". Ainda pondera que o planejamento "é um meio para programar as ações docentes, mas é também um momento de pesquisa e reflexão intimamente ligado à avaliação".

Nesse sentido, para a professora P2, o uso ou não do jogo pode fazer parte do planejamento, mas a adequação dos recursos utilizados muitas vezes dependerá do envolvimento do aluno na atividade.

A professora P3 diz que o planejamento com jogo deve estar relacionado ao conteúdo que pretende trabalhar com o aluno. Muitas vezes ela mesma elabora o jogo e outras vezes não.

Para as professoras P4 e P5, o jogo é utilizado para atender às necessidades ou dificuldades dos alunos. A professora $\mathrm{P} 4$ ainda explora o jogo para identificação das potencialidades do aluno e explica o procedimento utilizado com o uso de jogos dizendo:

primeiramente eu conheço os alunos, até que eu não conheço cada caso dou jogos livres (memória, pega varetas, dominó) e brincadeiras direcionadas, aí eu vou pegando o jeitinho deles e lendo os relatórios ou os laudos, vou vendo quais as dificuldades e através dos jogos livres eu vejo quais as potencialidades e a partir das potencialidades dessas crianças e as dificuldades eu elaboro esse plano, então a primeira coisa que eu faço é conhecê-los.

Os jogos podem ter várias funcionalidades, desde observação até planejamentos para intervenção (MACEDO; PETTY; PASSOS, 2010; KISHIMOTO et al., 2007). O professor pode observar a interação dos seus alunos em sala de aula com a atividade desenvolvida, e essa informação pode servir de fonte para o planejamento do trabalho docente, fornecendo mais conhecimento sobre cada aluno e possibilitando a decisão quanto ao encaminhamento mais apropriado no processo de ensino-aprendizagem.

Sobre o planejamento, ainda foram questionadas se o jogo está incluso no conteúdo proposto para o AEE. Todas as professoras responderam que sim. Para a professora P4, os conteúdos são pensados e trabalhados por meio dos jogos, uma vez que o jogo possibilita ao aluno aprender várias coisas: "por exemplo, eu posso trabalhar o social com o aluno TOD, os relacionamentos sociais, os conflitos, eu posso trabalhar as dificuldades de ortografia, posso trabalhar é a identificação, reconhecimento de letras do alfabeto".

De acordo com Andrade (2013), o jogo é considerado um caminho que conduz ao conhecimento do conteúdo didático específico, transcorrendo em uma transferência da ação lúdica para obtenção e desenvolvimento de informações.

Outra questão colocada às participantes foi se há diferenças do trabalho com jogos desenvolvidos no AEE em relação à prática desenvolvida pelo professor em sala de aula comum. As professoras relataram que sim, que existe essa diferença. A professora P1 disse que "as habilidades que os professores pensam em sala de aula, são com base nos conteúdos gerais da série"; ela, por sua vez, pensa nas habilidades que pretende desenvolver em específico naquele aluno. A professora P2 citou o número de alunos em sala como um fator que pode influenciar no trabalho proposto, o mesmo foi relatado pela professora P4: "na sala de aula são muitos alunos e dentro da sala de recursos, dentro do AEE são poucos, o que possibilita um trabalho mais direcionado".

$\mathrm{O}$ número de alunos na SRM permite ao professor oferecer-lhes um atendimento mais individualizado, com intervenções constantes. A professora P3 comentou que "o jogo por si só não tem sentido nenhum, então o jogo só tem sentido se você souber fazer as explorações necessárias nele", sendo assim, na sala de aula comum fica mais difícil realizar a intervenção em cada caso específico. A professora P5 também concordou que existe diferença no atendimento na sala regular em comparação ao realizado na SRM.

O jogo é um recurso indispensável para o processo de ensino-aprendizagem, e a intervenção do professor durante esse processo é que fará a diferença. Para trabalhar com jogos, o professor deve considerar alguns pontos e características importantes: objetivo, público, material, tempo, espaço, dinâmica, papel do adulto, proximidade de conteúdo, avaliação e continuidade (MACEDO; PETTY; PASSOS, 2010; LAVORSKI; VENDITTI JUNIOR, 2008).

As professoras responderam, ainda, sobre quais os jogos de mesa mais utilizados no AEE, todas elas citaram os seguintes jogos: Lince, Hora do Rush, Psicossol, Ligue 4, Trilha, Dominó, Dama, Cara a Cara, Quebra-cabeça. A professora P1 relatou que utiliza também jogos confeccionados por ela mesma para trabalhar alfabetização. A professora P2 afirmou utilizar o jogo Cara a Cara para trabalhar conteúdos como 
adjetivos e substantivos. A professora P3 disse que envolve no jogo Trilha conteúdos de matemática e português. A professora P4 descreveu que trabalha o Dominó com os alunos que têm dificuldade no raciocínio. A professora P5 explicou que trabalha com rimas para desenvolver nos alunos a consciência fonológica, e o jogo com palitos e material dourado para trabalhar contagem.

De acordo com Teixeira (2010, p. 49):

O jogo é um fator didático altamente importante: mais do que um passatempo, ele é elemento indispensável para o processo de ensino aprendizagem. Educação pelo jogo deve, portanto ser a preocupação básica de todos os professores que têm a intenção de motivar seus alunos ao aprendizado. O jogo quando bem utilizado torna-se um instrumento capaz de favorecer a reflexão do aluno, proporcionando a interação com determinado conteúdo de uma disciplina ou exploração de jogos educativos, seja virtuais ou não.

A utilização do jogo como instrumento pedagógico por si só, não resolve os problemas de aprendizagem, porém, é possível afirmar, pelas práticas vivenciadas e pelos relatos das professoras entrevistadas nesta pesquisa, que o jogo pode ser uma ferramenta valiosa para o processo de ensinoaprendizagem.

\subsection{Eixo 2: Perspectiva docente sobre o jogo e tecnologias na prática do AEE}

A tecnologia tem contribuído muito para o trabalho do professor em Sala de Recursos, tem possibilitado ao aluno desenvolver habilidades cognitivas importantes para o aprendizado de uma forma diversificada e prazerosa.

De acordo com Souza (2018, p.11):

Podemos inferir que os jogos educacionais digitais, sendo utilizado com fins pedagógicos, podem auxiliar no desenvolvimento da língua escrita e motora de sujeitos com deficiência intelectual, visto que, é um ambiente motivador que oferece diversas possibilidades de interação e isso foi comprovado ao proporcionar um ambiente educacional favorável ao desenvolvimento das habilidades cognitivas do aluno, possibilitando ao seu exercício potencial criativo.

Sendo assim, ao serem questionadas sobre como concebem a inclusão da tecnologia no AEE, as professoras entrevistadas relataram que a tecnologia é um instrumento valiosíssimo para o AEE. A professora P1 colocou a importância de se "fazer essa mescla, já que o aluno está inserido no contexto tecnológico", ao passo que P2 destacou que "tudo é tecnologia" e P3 salientou que "a tecnologia é fundamental também em todos os sentidos até mesmo para escrita de palavras, desenvolvimento do raciocínio nas situações de jogos e o desenvolvimento da digitação e leitura dos próprios textos".

Para a professora P4, "a inclusão da tecnologia é muito bem vinda, se for levar em consideração as dificuldades, a mobilidade reduzida, for levar em consideração a dificuldade de comunicação é muito bem vinda, porque a tecnologia abre um leque de oportunidades para atender essas necessidades". E na opinião da professora P5, "o jogo no computador, no tablet também é uma forma de atualizar, manter o mundo atual que as crianças vivem hoje".

Observa-se que a tecnologia é considerada pelas docentes como recurso importante para o atendimento aos alunos. A esse respeito, Souza (2016) pondera que a tecnologia oferece possibilidades para que as aulas sejam atraentes e interativas, para isso é necessário que o professor explore a tecnologia, sem medo, começando a usá-la por meio de atividades simples e seguras, para que, aos poucos, possa se sentir mais seguro e preparado para explorá-la a seu favor e do seu aluno.

Referente às novas tecnologias na educação escolar, a escola não pode ficar de fora deste momento de transformação social, pois as novas tecnologias são ferramentas que merecem ser acolhidas pela escola, questionando seus limites e suas potencialidades.

Segundo Figueiredo (2011), o cotidiano da escola e da sala de aula exige que o professor seja capaz de organizar as situações de aprendizagem levando em consideração a diversidade de seus alunos.

Outra questão colocada às participantes da pesquisa foi se utilizam jogos digitais no AEE e, se sim, quais seriam esses jogos. A professora P1 respondeu que coloca "sempre um jogo durante o atendimento, normalmente para finalizar, Educa jogos, Escola Games, Educação Dinâmica, Racha Cuca e o Noas". P2 disse: "procuro os jogos on-line como Friv". P3 asseverou que usa "o jogo Boole, o Darye". P4 assinalou que faz uso dos "jogos da Fazenda Rived". E P5 relatou: "gosto muito do jogo Arye, o Boole que eu até comprei também o material impresso, o Racha cuca, Fazenda Rived, e outros que a própria internet disponibiliza".

Observa-se que, de modo geral, as professoras utilizam os jogos digitais. No caso da professora P1, ela recorre ao jogo geralmente para finalizar o atendimento. A professora P2 ainda completou respondendo que costuma diferenciar entre atividade impressa, jogo de mesa e jogo digital. Já a professora P4 relatou que utiliza o jogo Fazenda Rived para fazer avaliação e trabalhar as potencialidades e dificuldades de seus alunos.

Independentemente do momento em que o jogo é utilizado, ou seja, no início, durante, ou no final do atendimento, em atividades avaliativas ou atividades cotidianas, o aspecto principal é o professor estar preparado para conduzir a utilização dos jogos digitais, pois não basta apenas incluir no planejamento o jogo como acessório, o foco dessa aplicação deve ser de potencializar a aprendizagem.

Ainda sobre as questões relativas a jogos e tecnologias, perguntou-se sobre como esses jogos chegam à SRM. A professora $\mathrm{P} 1$ relatou que teve acesso "Pesquisando sobre jogos e muitas indicações da professora da sala de informática". P2 encontrou informações "Buscando, fuçando, pesquisando, perguntando para as amigas", destacou ainda que a equipe de trabalho é muito unida. P3 relatou: "quando comecei na Sala de Recursos eu já tinha os jogos instalados no computador só tive acesso a eles". P4 salientou: "Alguns jogos digitais foram 
oferecidos pela Secretaria de Educação, outros eu fui atrás”. P5 disse que "Alguns a Secretaria de Educação passa pra gente através de $\mathrm{CD}$, outros por troca mesmo, ou procurando na internet".

As respostas das participantes mostraram o interesse das professoras em buscar novos instrumentos pedagógicos para favorecer o aprendizado dos alunos da geração atual, como foi destacado nas falas das professoras P1, P2, P4 e P5. Os jogos chegaram à SRM por meio de pesquisas, indicações da professora da sala de informática e da Secretaria Municipal de Educação, parceria importantíssima para o trabalho realizado por elas.

O professor precisa manter-se atualizado e em constante aprendizado para melhor exercer sua profissão, desse modo, pode: buscar meios para tornar o processo de ensino e aprendizagem mais significativo; utilizar os instrumentos tecnológicos e fontes de informação para adquirir e construir conhecimentos, favorecer o desenvolvimento do aluno; compreender que o papel do educador é selecionar os estímulos adequados, observando suas potencialidade e dificuldades, para o desenvolvimento completo do aluno. O professor deve estar sempre disposto a buscar novos meios para favorecer a aprendizagem do aluno (ZIVIANI, 2016).

A elaboração do plano de AEE direciona o trabalho do professor. Outra questão levantada foi como organizam um plano de AEE que inclui o jogo digital e com qual objetivo.

A professora P1 respondeu: "Segue o mesmo princípio dos jogos de mesa, primeiro eu penso nas habilidades a serem desenvolvidas, então pesquiso qual é o jogo que vai desenvolver aquele conteúdo ou habilidade". P2 relatou: "Procuro sempre mesclar um pouquinho, para o aluno não chegar e achar que só vai usar o computador. E tem aluno que não consegue compreender as regras, então eu trabalho com esse aluno, se durante a semana não respeitou as regras, conversamos, e se ele se comportar vai trabalhar esse mesmo conteúdo através do jogo". P3 disse: "Então o jogo digital utilizo para a alfabetização, que tem palavrinhas, são jogos de caça-palavras, jogos de organizar o alfabeto, de relacionar figuras com palavras". P4, por sua vez, explicou que, "dependendo da proposta que eu tenho com o aluno, o jogo ele é a motivação inicial, dependendo da proposta ele é a conclusão, então depende do que eu propus no plano de atendimento e depende da necessidade deste aluno". Segundo P5, o jogo "está sempre incluso a cada 15 dias, porque senão eles só querem ficar jogando no computador".

As professoras participantes relataram que o jogo digital está sempre incluso no plano de atendimento, no início como motivação ou no final do atendimento para fixar o conteúdo trabalhado, a prática do professor dependerá do plano de atendimento para a necessidade do seu aluno, das habilidades que seu aluno precisa desenvolver. Foi citado também como recompensa, ou seja, se o aluno se comportar terá direito a utilizar o computador. O jogo como recurso pedagógico, para trabalhar alfabetização, com caça-palavras, alfabeto, relacionar figuras com palavras, e depois sistematizar com a atividade escrita.

Aprender por meio de jogos - virtuais ou não - permite que o aluno compreenda o estudo de forma contextualizada, ou seja, o conhecimento sendo aplicado na prática. Para isso, fazse necessário que o professor tenha um plano de atendimento no qual os jogos sejam utilizados como encaminhamento ao conteúdo a ser trabalhado, como colaboradores da aprendizagem, e não como instrumento recreativo. Assim, os jogos devem ocupar um horário dentro do planejamento escolar, assim como afirmou P1: "penso nas habilidades e conteúdos a serem desenvolvidos".

Outra questão suscitada foi se elas têm alguma dificuldade em trabalhar com o jogo digital. As professoras P1, P3 e P5 relataram que não têm nenhuma dificuldade. A professora $\mathrm{P} 2$ disse que, "às vezes, por não ter conhecimento, falta tempo para pesquisar. Tenho dificuldade em instalar, fico com medo de estragar o computador". P4 expôs que "se tenho dificuldade eu nem coloco, eu prefiro trabalhar com jogos que eu tenho mais conhecimento. Confesso que tenho muito interesse em aprender novos jogos, mas falta tempo para ir atrás".

As professoras entrevistadas P1, P3 e P5 afirmaram que não apresentam dificuldade em trabalhar com o jogo digital. A professora $\mathrm{P} 2$ disse que às vezes tem dificuldade por não conhecer e receio na hora instalar o jogo, porém pede ajuda da professora de informática. E a professora $\mathrm{P} 4$ relatou que prefere trabalhar com jogos que ela já tem mais conhecimento do que ter insegurança em trabalhar com o jogo que ela não conhece; relatou ainda que tem interesse em aprender novos jogos, mas falta tempo para se capacitar.

A formação e a carga horária de trabalho são fatores que interferem na vida profissional do professor. Nos relatos supracitados das participantes, ficou claro que o tempo e a formação específica são fatores que interferem na atuação do professor em ter a tecnologia como apoio pedagógico. A esse respeito, Chaves (2004) ressalta que muitas vezes o professor sente dificuldades em lidar com novas tecnologias pela falta de conhecimento e tempo.

A seguir, as professoras foram questionadas se o trabalho com jogos digitais promove a aprendizagem do aluno e todas concordaram que sim. Para a professora $\mathrm{P} 1$, isto ocorre porque o jogo desperta o interesse e, no caso da aprendizagem, o jogo é relevante "porque a aprendizagem acontece pelo interesse, havendo interesse há abertura desse aluno para aprender". Em outras palavras, considera-se que uma pessoa está interessada quando ela tem vontade de aprender, desse modo, o que lhe é ensinado deve ser relevante para ela, isto é, deve responder a alguma dúvida, ou preencher uma necessidade.

Nesse contexto, a professora P3 pondera que o jogo "favorece não só a coordenação motora, mas, a atenção, percepção visual, a motricidade". Os aspectos do desenvolvimento em sentido integral são defendidos por vários autores, entre eles Bianchini, Arruda e Gomes 
(2015), ao asseverarem que, enquanto joga, a criança integra pensamento, ação física, sentimentos e aspectos sociais.

De acordo com a professora $\mathrm{P} 4$, o jogo digital "precisa estar relacionado a outros métodos de aprendizagem" e para a professora P5, "é uma forma de complementar o nosso trabalho". O jogo digital deve ser um recurso utilizado para diversificar o trabalho do professor, ou seja, sua função é complementar o plano de trabalho do professor para garantir a aprendizagem do aluno.

O jogo é uma ferramenta muito importante que contribui com a prática pedagógica do professor. Para Bomfoco e Azevedo (2013, p. 10), no caso dos “jogos eletrônicos, podem proporcionar experiências enriquecedoras, auxiliando na aprendizagem tanto na escola como fora dela".

Os jogos digitais, segundo os estudos de Gee (2009), promovem diversas formas de aprendizagem, não somente do conteúdo. Os jogos são importantes recursos pedagógicos que possibilitam ao aluno uma aprendizagem efetiva.

Outra questão formulada foi se, na opinião das professoras, os alunos gostam mais de jogos de mesa ou de jogos digitais.

$\mathrm{Na}$ opinião das professoras, P1 relatou que "Eles gostam dos dois, não têm uma preferência", para P2 "Digitais devido a nossa atual realidade, para os alunos tudo é computador, celular, tablet". P3 considerou que "o de mesa é muito atrativo, mesmo que seja um joguinho simples preparado pelo professor, motiva". P4 mencionou que "os alunos gostam mais dos digitais, no entanto eu proponho mais jogos de mesa, porque eu tenho visto que os jogos de mesa estão ficando perdidos diante da comodidade dos jogos digitais". E, na opinião da professora P5, os digitais são os preferidos. Os jogos digitais são os preferidos, segundo as professoras P2, P4, P5, a forma lúdica e divertida desperta no aluno a motivação, favorecendo a aprendizagem.

Percebe-se que a maioria das docentes respondeu que os alunos preferem os jogos digitais, embora a turma da professora P3 tenha preferência pelos jogos físicos de mesa. Um aspecto sobre a prática com jogos digitais e que chama atenção, está na resposta da professora $\mathrm{P} 4$, quando diz que mesmo seus alunos gostando mais dos jogos digitais, ela utiliza com maior frequência os jogos de mesa, porque ela considera que estes jogos estão "ficando perdidos diante da comodidade" dos jogos digitais.

Nesse sentido, considerar o tipo de jogo que desperta o interesse do aluno e relacioná-lo à aprendizagem pode ser um aspecto a ser revisto pela professora. Friedman (2002) ressalta um aspecto importante sobre os jogos, quando considera que a aprendizagem do aluno depende, em grande parte, de sua motivação: as necessidades e os interesses do aluno constituem a principal razão para que ele se ligue a uma atividade.

Para Rodrigues (2001, p.3), "O jogo é uma atividade rica e de grande efeito que responde às necessidades lúdicas, intelectuais e afetivas, estimulando a vida social e representando, assim, importante contribuição na aprendizagem", como também para inclusão (SASSAKI,
2010).

Outra questão muito importante é se, no caso do aluno do AEE, a tecnologia auxilia apenas como adaptação (Tecnologia Assistiva) ou como promotora da aprendizagem.

As professoras entrevistadas ressaltaram que utilizam a tecnologia como promotora da aprendizagem, no entanto, as professoras P4 e P5 utilizam a tecnologia tanto para promover a aprendizagem como também para adaptação de recursos da Tecnologia Assistiva. A tecnologia pode contribuir no processo de ensino tanto como ser promotora da aprendizagem como adaptação, nesse sentido, a Tecnologia Assistiva é considerada um recurso para atingir o objetivo maior que é a aprendizagem.

Tecnologia Assistiva é uma área do conhecimento, de característica interdisciplinar, que engloba produtos, recursos, metodologias, estratégias, práticas e serviços que objetivam promover a funcionalidade, relacionada à atividade e participação, de pessoas com deficiência, incapacidades ou mobilidade reduzida, visando sua autonomia, independência, qualidade de vida e inclusão social. (BRASIL, 2007, p.3).

A sociedade tem utilizado os recursos das Tecnologias Assistivas como mais um recurso na modalidade de Educação Especial, trazendo para a escola outra ferramenta de apoio ao ensino e aprendizagem dos educandos com deficiência.

\section{Conclusão}

O presente trabalho objetivou conhecer um pouco da prática do professor do AEE com jogos, bem como suas percepções com relação ao uso dos jogos e da tecnologia para aprendizagem dos alunos com NEE. Inicia-se a conclusão deste estudo com o seguinte questionamento: O que está em jogo quando se joga na SRM? Não seria a aprendizagem do aluno, e o jogo utilizado como um recurso alternativo de práticas diferenciadas na sala do ensino regular, conforme orienta a política nacional de Educação inclusiva?

Neste trabalho, com base em vários pesquisadores sobre o tema jogos e tecnologias, constatou-se que aspectos afetivos, cognitivos e sociais são ativados durante o jogo, por isso jogar é importante, na medida em que coloca em atividade todos os aspectos relacionados à aprendizagem e ao desenvolvimento do aluno. $\mathrm{O}$ aspecto motivacional do jogo é que convoca o aluno a pensar, planejar, analisar suas ações e revê-las, daí sua relevância.

Por outro lado, quando se trata de jogo e tecnologia, a geração atual caracteriza-se de modo diferente em relação à aprendizagem, ou seja, novos sentidos e objetos adquirem valor social para eles.

Por isso, quando se pensa em práticas inclusivas, é essencial refletir sobre quais recursos serão inclusivos para o aluno, mas também como os professores os concebem, no caso em questão: jogos e tecnologias. Contextos inclusivos de aprendizagem perpassam olhares de apoio não apenas ao aluno, mas também ao professor, uma vez que todos os envolvidos mudam e constroem sentidos continuamente sobre 
a aprendizagem.

De modo geral, as cinco professoras entrevistadas consideram os jogos importantes e por esta razão os incluem em seu planejamento no AEE. O acesso aos jogos é realizado por meio de pesquisas que as docentes realizam e também há jogos que são disponibilizados pela Secretaria da Educação. A maioria das professoras participantes relatou que sabe utilizar os jogos digitais, embora duas docentes (P2 e P4) manifestaram ter dificuldades, por falta de conhecimento e tempo para se dedicar à aprendizagem de determinado jogo.

A formação e a carga horária de trabalho são fatores que interferem na vida profissional do professor. Nos relatos das participantes, ficou claro que o tempo e a formação específica podem interferir na atuação do professor em ter a tecnologia como apoio pedagógico.

Foi possível concluir, assim, que a aplicação de propostas inclusivas com jogos e tecnologias perpassa a concepção docente sobre integração das NTIC e jogos nas SRMs, uma vez que o modo como os docentes concebem tais recursos decorrerá na ação prática do jogo.

Estudos sobre percepções na escola demandam compreensão de que prática, recursos e sentidos interatuam no modo significativo e podem abrir caminho ou não para novas propostas.

\section{Referências}

ANDRADE, S.S. O lúdico na vida e na escola: desafios metodológicos. Curitiba: Appris, 2013.

BIANCHINI, L.G.B.; ARRUDA, R.B.; GOMES, L.R. Ludicidade e educação. Londrina: Educacional, 2015.

BOMFOCO, M.A.; AZEVEDO, V.A. Jogos eletrônicos em foco: encontros entre os princípios de aprendizagem e as inteligências múltiplas. Renote, v.11, n.1, p.1-11, 2013.

BRASIL. Comitê Nacional de Educação em Direitos Humanos. Plano Nacional de Educação em Direitos Humanos. Brasília: Secretaria Especial dos Direitos Humanos, Ministério da Educação, Ministério da Justiça, UNESCO, 2007.

BRASIL. Ministério da Educação. Política Nacional de Educação Especial na Perspectiva da Educação Inclusiva. Brasília: MEC, 2008 .

CHAVES, E. Tecnologia na educação. 2004. Disponível em: http://chaves.com.br/TEXTSELF/EDTECH/tecned2.htm\#II. Acesso em: 12 jun. 2020.

COELHO, V.M. O jogo como prática pedagógica na escola inclusiva. Santa Maria: Universidade Federal de Santa Maria, 2010.

COTONHOTO, L.A.; ROSSETTI, C.B.; MISSAWA, D.D.A. A importância do jogo e da brincadeira na prática pedagógica. Construção Psicoped., v.27, n.28, p.37-47, 2019.

DIESEL, A. et al. Tecnologias de informação e comunicação no compartilhamento de aprendizagens na educação básica. Rev. Iberoam. Estud. Educ., v.13, n.1, p.59-77, 2018.

DUK, C. Educar na diversidade: material de formação docente. Brasília: MEC, SEESP, 2006.

EVANGELISTA, V.M.A. Paraísos virtuais: um estudo sobre jogos eletrônicos e moralidade no mundo contemporâneo. 2018.
242 f. Tese (Doutorado em Psicologia) - Faculdade de Ciências e Letras, Universidade Estadual Paulista, Assis, 2018.

FIGUEIREDO, R.V. A formação de professores para inclusão dos alunos no espaço pedagógico da diversidade. In: MANTOAN, M.T.E. O desafio das diferenças nas escolas. Petrópolis: Vozes, 2011. p. 139-147.

FRIEDMAN, A. Brincar, crescer e aprender: o resgate do jogo infantil. São Paulo: Moderna, 2002.

GEE, J. P. Bons videogames e boa aprendizagem. Rev. Perspectiva, v.27, n.1, p.167-178, 2009.

GOMES, A.A. A construção da identidade profissional do professor: uma análise de egressos do curso de Pedagogia. In: CONGRESSO PORTUGUÊS DE SOCIOLOGIA, 6., 2008, Lisboa. Anais. Lisboa: UNL, 2008. p.1-15. Disponível em: http:// www.aps.pt/vicongresso/pdfs/590.pdf. Acesso em: 22 jan. 2020.

GRASSI, T.M. Oficinas psicopedagógicas. Curitiba: Ibpex, 2008.

KASSAR, M.C.M. Educação especial na perspectiva da educação inclusiva: desafios da implantação de uma política nacional. Educar Rev., n. 41, p.61-79, 2011.

KISHIMOTO, T.M. et al. Jogo, brinquedo, brincadeiras e a educação. São Paulo: Cortez, 2007.

LAVORSKI, J.; VENDITTI JUNIOR, R. A Ludicidade no desenvolvimento e aprendizagem da criança na escola: reflexões sobre a educação física, jogo e inteligências múltiplas. Rev. EFDEPORTES, v.13, n.119, 2008. Disponível em: https://www. efdeportes.com/efd119/a-ludicidade-no-desenvolvimento-eaprendizado-da-crianca-na-escola.htm. Acesso em: 30 jun. 2020.

LÉVY, P. Cibercultura. São Paulo: Editora 34, 2010.

LIBÂNEO, J.C. Didática. São Paulo: Cortez, 2013.

MACEDO, L. Ensaios pedagógicos: como construir uma escola para todos? Porto Alegre: Artmed, 2007.

MACEDO, L.; PETTY, A.L.S.; PASSOS, N.C. Os jogos $e o$ lúdico na aprendizagem escolar. Porto Alegre: Artmed, 2005.

MACEDO, L.; PETTY, A.L.S.; PASSOS, N.C. Quatro cores, senha e dominó: oficinas de jogos em uma perspectiva construtiva e psicopedagógica. São Paulo: Casa do Psicólogo, 2010.

MARTINS, V.; BRIDI, M. Dos games para a sala de aula: TIC, literatura e educação. Rev. Sistemas, Cibernética Inform., v.13, n.1, p.54-59, 2016.

MINAYO, M.C.S. Análise qualitativa: teoria, passos e fidedignidade. Ciênc. Saúde Coletiva, v.17, n.3, p.621-626, 2012.

MORAN, J. Mudando a educação com metodologias ativas. In: SOUZA, C.A.; MORALES, O. E.T. Convergências midiáticas, educação e cidadania: aproximações jovens. Ponta Grossa: Foca Foto; PROEX/UEPG, 2015. p.15-33.

NÓVOA, A. (org.). Os professores e sua formação. Lisboa: Dom Quixote, 1997.

PINHEIRO, A.J.M. Atividade lúdica e hábitos digitais: um estudo com acadêmicos em processo de formação no curso de pedagogia EaD. 2020. 96f. Dissertação (Mestrado em Metodologias para o Ensino de Linguagens e suas Tecnologias) - Universidade Pitágoras Unopar, Londrina, 2020.

RODRIGUES, M. O desenvolvimento do pré-escolar e o jogo. Petrópolis: Vozes, 2001.

SASSAKI, R.K. Inclusão: construindo uma sociedade para todos. Rio de Janeiro: WVA, 2010.

SILVA, V.L.G. Profissão: professora. In: CAMPOS, M.C.S.S.; SILVA, V.L.G. Feminização do magistério: vestígios do passado 
que marcam o presente. Bragança Paulista: Edusf, 2002. p. 95122.

SOUZA, C.J. Plataformas de aprendizagem: sentidos construídos nos cursos de formação para docente da educação básica em relação ao uso das novas tecnologias integradas ao processo de ensino e aprendizagem. 2016. 111 f. Dissertação (Mestrado em Metodologias para o Ensino de Linguagens e suas Tecnologias) Universidade Norte do Paraná, Londrina, 2016.

SOUZA, E.D. Um relato de experiência do uso dejogos educativos com um aluno com deficiência intelectual. In: CONGRESSO INTERNACIONAL DE EDUCAÇÃO E TECNOLOGIAS, ENCONTRO DE PESQUISADORES EM EDUCAÇÃO A DISTÂNCIA - CIET-EnPED, 2018, São Carlos. Anais [...]. São Carlos: CIET-EnPED, 2018. p. 1-13.
SPURIO, M. S. Jogos digitais na atuação do professor do Atendimento Educacional Especializado. 2019.105 f. Dissertação (Mestrado em Metodologia para o Ensino de Linguagens e suas Tecnologias) - Universidade Pitágoras Unopar, Londrina, 2019.

TEIXEIRA, C. E. J. A ludicidade na escola. São Paulo: Loyola, 2010.

VALENTE, J.A.; ALMEIDA, M.E.B.; GERALDINI, A.F.S. Metodologias ativas: das concepções às práticas em distintos níveis de ensino. Rev. Diálogo Educ., v.17, n.52, p.455-478, 2017.

ZIVIANI, M. C. N. Interdependência e colaboração em contextos escolares inclusivos. 2016. 162 f. Dissertação (Mestrado em Educação) - Universidade Federal do Espírito Santo, Vitória, 2016. 